\title{
Developing Critical Collaboration Skills in Engineering Students: Results from an Empirical Study
}

\section{Dr. Pilar Pazos, Old Dominion University}

Pilar Pazos is an Associate Professor in the Department of Engineering Management and Systems Engineering at Old Dominion University, Norfolk, VA, USA. Her main areas of research interest are collaborative work-structures, virtual teams and team decision-making and performance.

Ms. Nina Magpili, Engineering Management \& Systems Engineering (EMSE), Old Dominion University

Nina Magpili is a Ph.D. candidate and graduate research and teaching assistant at Engineering Management and Systems Engineering (EMSE) department at Old Dominion University. Her dissertation explores deep-level diversity (MBTI, decision-making styles and communication styles) in virtual team decision making. Her other research interests include online collaboration technologies, team building, self-managing teams, and sociotechnical systems.

\section{Mr. Zikai Zhou, Old Dominion University}

Zikai Zhou is a PhD student in Old Dominion University and his research interests are about team collaboration and cognition analysis.

\section{Dr. Luis Jose Rodriguez, Naval Surface Warfare Center Dahlgren Division}

Luis J. (LJ) Rodriguez, D.Eng., is a manager at the Naval Surface Warfare Center Dahlgren Division (NSWCDD). He is also an adjunct professor within the Engineering Management and Systems Engineering Department at Old Dominion University in Norfolk, Virginia. He holds a Doctor of Engineering degree and a Masters of Engineering Management (M.E.M.) from Old Dominion University, as well as a B.S. degree in Mechanical Engineering from the University of Puerto Rico-Mayaguez. 


\title{
Developing critical collaboration skills in engineering students: Results from an experimental study
}

\begin{abstract}
In highly technical organizations, work is becoming increasingly distributed; requiring practicing engineers to master virtual collaboration skills while acquiring expertise in a range of collaboration technologies. Although there has been great emphasis on developing collaboration competencies in the engineering curriculum, empirical evidence of successful strategies for distributed team settings is scarce. As an attempt to fill this gap this study investigates the impact of a scalable intervention in developing virtual collaboration skills. The intervention, based on instructional scaffolds embedded with collaboration technologies, is aimed at supporting specific processes including planning, goal setting, clarifying goals and expectations, communication, coordination and progress monitoring. A quasi-experimental design was used to evaluate the impact of the intervention on student teamwork skills. Data from 278 graduate and undergraduate engineering students participating in virtual team projects was used in the analysis. Results from the analysis are presented suggesting a statistically significant impact of the intervention on self-management skills when comparing randomly assigned teams with and without the intervention. The intervention is designed to be scalable so that it can be embedded into existing project-based courses. Our findings have important implications for the development of teamwork skills in engineering courses and provide evidence of a successful strategy that can be integrated into the existing engineering curriculum.
\end{abstract}

\section{Keywords}

Virtual teams, team effectiveness, information and communication technologies, engineering education, collaborative learning

\section{Introduction}

The ability to work on multi-disciplinary teams has long been considered a critical skill for engineers to succeed in a globalized and rapidly changing business environment. ${ }^{1,2}$ Most companies in the current work environment use distributed teams as an integral part of their business processes and activities, which often rely on information and communication technologies (ICT) to collaborate from remote locations.

Academic programs increasingly recognize professional skills such as teamwork and communication skills as critical competencies required for future engineers. ${ }^{3,4}$ As a result, many engineering courses have being designed to incorporate a team element such as Columbia University's Gateway design course, ${ }^{5}$ Massachusetts Institute of Technology's undergraduate design course and its "New Products Program" and Rowan University's Engineering Clinics Program. $^{7}$

Teamwork structures in most organizations increasingly rely on ICT with often-minimal direct personal contact among team members. However, most existing engineering programs don't fully incorporate the learning opportunities for students to master technology-supported teamwork as a core element of the curriculum. ${ }^{8,9}$ Also, we have found that in general, there is little understanding of the role of technology on supporting collaborative learning outcomes. ${ }^{8}$ 
Although numerous efforts have been made to promote the development of teamwork skills, a recent review of research on engineering student teams suggests that our understanding of how best to cultivate and assess collaborative learning outcomes in engineering students is not well understood. ${ }^{11}$

\section{Theoretical Foundation}

Working in teams requires that students learn how to interact with each other while sharing and processing information in a collaborative learning environment. Collaborative work largely reflects the authentic environment in engineering-intensive organizations that often rely on teambased structures to solve engineering problems. Providing similar opportunities as part of the engineering curriculum becomes important to prepare future engineers to thrive in this environment. By carefully constructing guidance to learners, educators can provide the necessary structure and tools to ensure the appropriate degree of challenge and direction is provided to groups and individuals. Prior research suggests that learning can be best facilitated by scaffolded instruction that supports collaboration and interaction in authentic environments using state of the art tools and processes. ${ }^{8}$ Scaffolds are defined as instructional and expert support in the guise of feedback, directions or guided instructional materials and tools embedded in instructional activities. Scaffolding has been identified as a powerful approach to support learning in complex collaborative environments. ${ }^{10,12}$ Through scaffolding, learners can accomplish complex and ambiguous tasks that otherwise may not be able to successfully complete on their own. ${ }^{12}$ Providing this expert support for learners was found to be more effective for transferring knowledge than unsupported instruction. It is our belief that this finding is particularly applicable to collaborative learning in virtual teams due to the increased complexity of remote collaboration. ${ }^{10}$

The structure and learning goals of the instructional scaffolds were evidence-based and built upon our foundational knowledge of team processes and team effectiveness. ${ }^{17-21}$ The specific scaffolds were developed to map a team process framework proposed by Marks et al. ${ }^{17}$; which has been accepted in subsequent literature as one of the most solid model for understanding the processes involved in effective teamwork. ${ }^{18,19}$ Through this framework, team processes can be classified as action, transition and interpersonal processes. ${ }^{17}$ The designed intervention focused on supporting specific transition and action processes. Transition processes relate to preparation for work accomplishment whereas action processes involve the actual execution of the task. The intervention was designed to provide support for key transition and action processes that are known to drive team effectiveness. Definitions of the types of action and transition processes from the team literature and the associated scaffolds used as part of the intervention evaluated in this study are presented in Table 1. The last column in the table indicates the specific element of the intervention that was designed and utilized to support each team process. The scaffolds included cognitive tasks such as an activity focused on the development of shared mental model or team identity, artifacts such as a team charter, and tools in the collaborative platform such as web-conferencing or document repository. The artifacts included in the last column of table 1 such as team charter, project plan and communication strategy were incorporated as guided activities, which included a set of guiding questions or templates that students were required to complete. Students would access either a template or a tool in the collaborative site to complete the activity. For instance, a template of the team charter was accessible through the collaborative 
site and the teams would access the template, develop their charter based on the template and upload the final version.

This paper explores the impact of a scalable intervention that combines the use of a web-based collaborative platform with embedded instructional scaffolds aimed at supporting team processes. A key contribution of this study is that the intervention was developed based on stateof-the-art knowledge on team effectiveness from the industrial, behavioral and cognitive psychology fields, as well as technology appropriation and acceptance theories from the field of Management Information Systems. ${ }^{17-22,23}$ The instructional approach using scaffolds is guided by principles from social-constructivist learning theory. The intervention was designed to support specific cognitive and behavioral team processes such as defining goals, roles and expectations, team monitoring, behavioral integration, consensus building and conflict resolution. ${ }^{7}$ The collaboration tool was design using the principles of task-technology fit and technology appropriation to provide easily accessible tools that best align with the specific activity or task that teams need to accomplish at different states of the project.

Table 1. Instructional Scaffolds and Associated Teamwork Processes

\begin{tabular}{|c|c|c|c|}
\hline & $\begin{array}{c}\text { Process } \\
\text { Dimensions }\end{array}$ & Process Definition & $\begin{array}{c}\text { Process Scaffolds } \\
\text { (cognitive tasks, tools and artifacts) }\end{array}$ \\
\hline \multirow{2}{*}{ 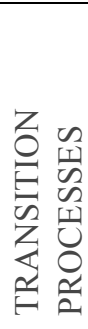 } & $\begin{array}{l}\text { Mission } \\
\text { analysis, goal } \\
\text { formulation } \\
\text { and planning }\end{array}$ & $\begin{array}{l}\text { Identification of team's main tasks, the } \\
\text { operative environmental conditions and } \\
\text { resources available. Identification and } \\
\text { prioritization of goals and sub goals for } \\
\text { mission accomplishment }\end{array}$ & $\begin{array}{c}\text { Team Charter (artifact) } \\
\text { Project plan (artifact) } \\
\text { Shared mental model and team identity } \\
\text { building (cognitive task) }\end{array}$ \\
\hline & $\begin{array}{l}\text { Strategy } \\
\text { formulation }\end{array}$ & $\begin{array}{l}\text { Development of alternative courses of } \\
\text { action for mission accomplishment }\end{array}$ & $\begin{array}{l}\text { Communication strategy (artifact) } \\
\text { Project plan (artifact) }\end{array}$ \\
\hline \multirow{4}{*}{ 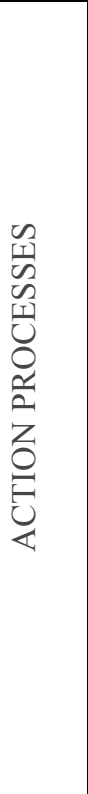 } & $\begin{array}{c}\text { Monitoring } \\
\text { progress } \\
\text { toward goals }\end{array}$ & $\begin{array}{l}\text { Tracking task and progress toward mission } \\
\text { accomplishment, interpreting system } \\
\text { information in terms of what needs to be } \\
\text { accomplished for goal attainment, and } \\
\text { transmitting progress to team members }\end{array}$ & $\begin{array}{c}\text { Task tracking (tool) } \\
\text { Web conferencing (tool) } \\
\text { Task status updates (tool) } \\
\text { Team mid-project evaluation (artifact) }\end{array}$ \\
\hline & $\begin{array}{l}\text { Systems } \\
\text { monitoring }\end{array}$ & $\begin{array}{l}\text { (1) internal systems monitoring (tracking } \\
\text { personnel, equipment, and information), } \\
\text { and (2) environmental monitoring } \\
\text { (tracking the team's environmental } \\
\text { conditions) }\end{array}$ & $\begin{array}{c}\text { Web conferencing (tool) } \\
\text { Document repository (tool) } \\
\text { Team activity tracking (tool) } \\
\text { Information exchange indicator (tool) } \\
\text { Project plan (artifact) }\end{array}$ \\
\hline & $\begin{array}{l}\text { Team } \\
\text { monitoring } \\
\text { and backup } \\
\text { behavior }\end{array}$ & $\begin{array}{l}\text { Assisting team members to perform their } \\
\text { tasks. Assistance may occur by (1) } \\
\text { providing a teammate feedback/coaching, } \\
\text { (2) helping a teammate in carrying out } \\
\text { actions, or (3) assuming and completing a } \\
\text { task for a teammate }\end{array}$ & $\begin{array}{c}\text { Web conferencing (tool) } \\
\text { Mid project peer evaluation (artifact) } \\
\text { Project plan (artifact) } \\
\text { Team Charter (artifact) }\end{array}$ \\
\hline & Coordination & $\begin{array}{l}\text { Executing and orchestrating the sequence } \\
\text { and timing of interdependent actions }\end{array}$ & $\begin{array}{l}\text { Project plan evaluation and adjustment } \\
\text { (artifact and cognitive task) }\end{array}$ \\
\hline
\end{tabular}




\section{Research Methodology}

A quasi-experimental research study was conducted to address the following research question: What is the impact of the intervention (collaborative tool and associated instructional scaffolds) on teamwork competencies?

The intervention incorporates the use of a web-based information and communication technology (ICT) tool to support virtual collaboration with embedded instructional scaffolds designed to support team processes in the context of a group project in engineering courses (see table 1). The intervention was designed to be applicable to most courses and independent of the subject matter as long as there is a significant team project component. The web-based collaboration platform includes tools and artifacts such as team profile, team charter, project plan, web-conferencing, message board, automatic reminders, project repository, task progress tracking, etc. The instructional scaffolds were developed during Spring 2014 and baseline data was collected during four consecutive semesters from 278 undergraduate and graduate students from the College of Engineering at a mid-Atlantic public university. Students were recruited from courses with a hybrid instructional delivery with some students present on campus and others attending live via web-based technology. All the participating students were part of a virtual team with at least two remote members.

The implementation of the web-based tool and associated scaffolds required some coursespecific customization because the nature of the class project, the context and complexity varied between the two courses. The first course is required for all undergraduate engineering students and the team project was completed within a 6 -week period. It accounted for $45 \%$ of the grade. In the graduate level course, the project was completed in 9 weeks and it accounted for $55 \%$ of the grade.

This study focused on examining the intervention as a whole rather than looking at individual tools or artifacts. The analysis was aimed at evaluating the impact of the intervention on teamwork skills by comparing treatment (team project using the collaboration tool and scaffolds) and control condition (virtual team project with traditional approach) using prior teamwork experience in student teams and work teams as a control variable to account for possible preexisting differences. The comparison used the same courses, identical projects and instructors.

The Teamwork KSA instrument was used to measure teamwork competencies. This instrument is the most widely accepted and used quantitative assessment of team competencies. ${ }^{21,24,25}$ McClough and Rogelberg found that the teamwork-KSA test successfully predicted individual team member behavior such that higher scores on the teamwork-KSA test were associated to greater individual effectiveness within teams. ${ }^{26}$ Their research provided evidence of the validity of the teamwork KSA measurement to assess teamwork competencies. The specific competencies that will be evaluated in this paper are self-management skills and interpersonal skills. Next we define the variables and specific metrics used to assess each variable.

\section{Variables}

This section presents the variables that were explored in this study along with their operational definitions.

\section{Dependent variables}


The response variables measured in this study were teamwork knowledge, skills and abilities (KSAs). This variable was further broken down into two subscales, self-management KSAs and interpersonal KSAs. Table 2 further describes the elements included under the two categories of self-management and interpersonal skills.

Self-management KSA measures the ability to set goals, manage performance and plan and coordinate the work.

Interpersonal KSAs measures the ability to set collaborative problem solving, communication and conflict resolution.

Table 2. Description of Teamwork KSAs (Adapted from Stevens and Campion) ${ }^{24,25}$

\section{Self-management KSAs}

1. Goal Setting and Performance Management KSAs. Assessment of competencies related to establishing specific, challenging, and accepted team goals; and monitoring, evaluating, and providing feedback on both overall team performance and individual team member performance.

2. Planning and Task Coordination KSAs. Assessment of competencies related to coordinating and synchronizing activities, information, and tasks between team members, as well as aiding the team in establishing individual task and role assignments that ensure the proper balance of work- load between team members.

Interpersonal KSAs

3. Conflict Resolution KSAs. Assessment of competencies related to recognizing types and sources of conflict; encouraging desirable conflict but discouraging undesirable conflict; and employing integrative (win-win) negotiation strategies rather than distributive (win-lose) strategies.

4. Collaborative Problem Solving KSAs. Assessment of competencies related to identifying situations requiring participative group problem solving and using the proper degree of participation; and recognizing obstacles to collaborative group problem solving and implementing appropriate corrective actions.

5. Communication KSAs. Assessment of competencies related to understanding effective communication networks and using decentralized networks where possible; recognizing open and supportive communication methods; maximizing the consistency between nonverbal and verbal messages; recognizing and interpreting the nonverbal messages of others; and engaging in and understanding the importance of small talk and ritual greetings.

\section{Covariates}

The analysis included two control variables to account for prior student team experience and prior work team experience in industry. Prior experience working in student teams was assessed using a 2-item scale including the following items: "I have prior experience working on team projects for classes" and "I have prior experience working on virtual team projects for classes". Prior team experience outside the classroom was assessed using a 3-item measure including: "I possess prior experience managing a project team in industry", "I have prior experience managing others" and "I have prior experience in work teams".

\section{Research hypotheses}

H1: There is a positive impact of the intervention on student teamwork skills

$\mathrm{H} 2$ : There is a positive impact of the intervention on student self-management skills

$\mathrm{H} 3$ : There is a positive impact of the intervention on student interpersonal skills

\section{Sample and Method}

A quasi-experimental design was conducted to evaluate the impact of the collaboration platform (web-based technology and associated instructional scaffolds) on self-management and interpersonal skills. The analysis compared two random samples of participating teams that were assigned to either the treatment or the control. The treatment condition included students completing the projects using the intervention. The control included students completing the 
same projects in a traditional way using Blackboard and any other ad-hoc tools they selected to support their collaboration. Control and treatment conditions used the same courses and same assignments. The only difference between the treatment and the control groups is that the former used the collaboration tool and scaffolds to support collaborative activities while teams in the control did not. The type of projects they worked on was the same across treatment and control. All the teams in both conditions were created using stratified random sampling to ensure that members of every team were remotely located. Table 1 outlines the instructional scaffolds used in the treatment condition. Participants were recruited from 13 classes over 4 consecutive semesters. During the first two semesters data was collected under the control condition for all the courses, while the last two semesters data was collected under the treatment condition. The undergraduate courses included Project Management, Engineering Ethics, Introduction to Engineering Management and the graduate course included Project Management and Systems Analysis. All courses have a team project that accounts for at least $45 \%$ of the total course grade. The students in the treatment condition received an in-class 30-minute training module on the use of the tool and they were also given access to a training video accessible directly from the collaborative tool. A graduate teaching assistant was assigned to address technical questions regarding the tool.

Next, we describe the samples used to test the hypotheses. Course sections were assigned to either control or treatment condition:

- Control group: baseline data collection using the same courses and projects as the treatment without using the collaboration platform and associated scaffolds.

- Treatment group: students enrolled in the same selected courses participating in the same type of projects using the collaboration platform and associated instructional scaffolds.

The analysis evaluated the impact of the intervention on teamwork KSA and the two subscales (self-managing skills and interpersonal skills). Prior psychometric studies of the teamwork KSA test suggest studies can include the overall and also the two subscales. ${ }^{26}$ The final data set included 245 responses.

\section{Results}

Analysis of Covariance (ANCOVA) was conducted to determine whether the intervention had a statistically significant impact on teamwork skills. The level of significant used for the analysis was $\alpha=0.05$. First, we conducted a t-test to determine whether there were any pre-existing differences in prior teamwork experience between treatment and control groups. Results from the test suggest that there were no significant differences between both groups prior to participating in the study as can bee seen in Table 3 .

Table 3. Mean and Standard Deviation for the Covariates in the Control and Treatment Groups

\begin{tabular}{llllll} 
& \multicolumn{3}{c}{ Control $\mathrm{n}=80$} & \multicolumn{2}{c}{ Treatment $\mathrm{n}=165$} \\
\cline { 2 - 6 } & Mean & Std. Dev. & Mean & Std. Dev. & p-value \\
\cline { 2 - 6 } Team management experience & 5.60 & 1.508 & 5.44 & 1.2889 & 0.650 \\
Student team experience & 5.49 & 1.572 & 5.15 & 1.626 & 0.990
\end{tabular}

ANCOVA analysis was used to test the research hypotheses. Hypothesis 1 tested the impact of the intervention on teamwork skills controlling for prior team experience. We found evidence of 
a significant impact of the intervention on teamwork KSAs $(F=4.034, p=0.046)$, that is, students that went through the intervention displayed a significantly higher ability to manage team projects than those in the control group. Table 4 displays the estimated mean and standard deviation of self-managing skills for treatment and control groups.

Table 4. Estimated Mean and Standard Error for teamwork KSAs

\begin{tabular}{lcc} 
& Control & Treatment \\
\hline Mean & 19.72 & 21.16 \\
\hline Std. Error & .624 & .344 \\
\hline
\end{tabular}

The values displayed in Table 4 indicates a mean difference of 1.44 in favor of the students that used the collaboration platform and scaffolds in their projects, representing a $7 \%$ difference in teamwork skills. This difference was adjusted for pre-existing differences in teamwork experience. One could argue that this is a sizable difference considering that the intervention only took place over less than 12 weeks. The observed power of the analysis for the graduate sample was 0.6 .

Hypothesis 2 and 3 tested the impact of the intervention on the self-managing and interpersonal skills sub-scales respectively using the same type of analysis as in Hypothesis 1. Results indicate that students in the treatment condition scored significantly higher than those under the control condition in self-managing skills $(\mathrm{F}=5.067, \mathrm{p}=0.016$, power $=0.7)$. On average, students in the treatment condition scored $9 \%$ higher on average than those in the control group when controlling for previous teamwork and team management experience. Sample statistics for treatment and condition are shown in Table 5.

Table 5. Estimated Mean and Standard Error for self-managing KSAs

\begin{tabular}{lcc} 
& Control & Treatment \\
\hline Mean & 6.46 & 7.03 \\
\hline Std. Error & .207 & .114 \\
\hline
\end{tabular}

Hypothesis 3 tested the impact of the intervention on the subscale of interpersonal skills. Results suggest that the intervention did not have a significant impact on interpersonal skills $(\mathrm{F}=2.236$, $\mathrm{p}=0.136$ ). The observed power of this analysis was 0.42 .

\section{Conclusions and Implications}

Teamwork skills have been identified as critical competencies for engineering students and numerous efforts have been ongoing over the years to develop these skills as part of the engineering curriculum. ${ }^{1,2}$ This study builds on these efforts by empirically evaluating an evidence-based intervention aimed at improving these skills in distributed student teams without face-to-face interaction. Teamwork skills are measured using a validated instrument that has been widely used for competency assessment. We provide a detailed description of an intervention that achieved a significant improvement of these critical abilities in a large sample 
of students at the undergraduate and graduate level. We found a positive impact on overall teamwork knowledge, skills and abilities and there was also a positive impact on selfmanagement skills. Self-managing skills are germane to the everyday job of professional engineers as they include knowledge and abilities related to goal setting, performance monitoring and evaluation, planning and role assignment among others.

We found that the proposed intervention, which combined the use of ICT with instructional scaffolds, is a very promising approach to support the development of critical skills for future professional engineers. The collaboration platform was designed to align with state of the art knowledge of team effectiveness as well as theoretical foundations in technology use and acceptance from the management information systems literature. ${ }^{17-22,23}$ The instructional scaffolds were purposely designed and implemented to support critical teamwork processes that are known to affect the effectiveness of teams. The overall intervention (collaborative tool and instructional scaffolds) targeted typical barriers faced by virtual teams such as lack of shared identity, lack of cohesion and tendency to free ride. Our preliminary results from a large sample of engineering students has shown that teamwork skills can be developed using collaboration tools and instructional scaffolds embedded in existing courses. The proposed intervention is potentially scalable into most project-based course that have a large team project component. Future research could evaluate the impact of similar intervention in a larger sample of courses and disciplines. The proposed intervention could also be used as a key element in distance learning courses to support collaborative work while developing teamwork skills in these types of settings.

\section{Acknowledgements}

This material is based upon work supported by the National Science Foundation under Grant No. 1340407.

\section{References}

1. Prados, J.W. “The Editor's Page: Engineering Criteria 2000- A change Agent for Engineering Education”. Journal of Engineering Education, 85, no. 4 (1997).

2. Shuman, Larry J., Mary Besterfield-Sacre, and Jack McGourty. "The ABET "professional skills"-Can they be taught? Can they be assessed?." Journal of Engineering Education, 94, no. 1 (2005): 41-55.

3. Passow, Honor J. "Which ABET competencies do engineering graduates find most important in their work?." Journal of Engineering Education, 101, no. 1 (2012): 95.

4. Prados, John W., George D. Peterson, and Lisa R. Lattuca. "Quality assurance of engineering education through accreditation: The impact of Engineering Criteria 2000 and its global influence." Journal of Engineering Education, 94, no. 1 (2005): 165-184

5. McGourty, Jack, James Reynolds, L. Shuman, M. Besterfield-Sacre, and Harvey Wolfe. "Using multisource assessment and feedback processes to develop entrepreneurial skills in engineering students." Proceedings of the American Society for Engineering Education Conference. 2003.

6. $\quad$ Durfee, William K. "Engineering education gets real." Technology Review, 97 (1994): 42-42.

7. Dahm, Kevin D., James A. Newell, and Heidi L. Newell. "Rubric development for assessment of undergraduate research: Evaluating multidisciplinary team projects." In CD) Proceedings of the American Society for Engineering Education Conference. 2003.

8. Whitman, Lawrence E., Don E. Malzahn, Barbara S. Chaparro, Mark Russell, Rebecca Langrall, and Beth A. Mohler. "A Comparison of Group Processes, Performance, and Satisfaction in Face-to-Face 
Versus Computer-Mediated Engineering Student Design Teams." Journal of Engineering Education, 94, no. 3 (2005): 327-337.

9. Zhou, Zikai and Pazos, P. "Managing Engineering Capstone Design Teams: A Review of Critical Issues and Success Factors." In IIE Annual Conference. Proceedings, p. 3006. Institute of Industrial EngineersPublisher, 2014.

10. Kirschner, Paul A., John Sweller, and Richard E. Clark. "Why minimal guidance during instruction does not work: An analysis of the failure of constructivist, discovery, problem-based, experiential, and inquiry-based teaching." Educational Psychologist, 41, no. 2 (2006): 75-86.

11. Borrego, Maura, Jennifer Karlin, Lisa D. McNair, and Kacey Beddoes. "Team effectiveness theory from industrial and organizational psychology applied to engineering student project teams: A research review." Journal of Engineering Education, 102, no. 4 (2013): 472-512.

12. Vygotsky, Lev Semenovich. Mind in society: The development of higher psychological processes. Harvard University Press, 1980.

13. Tien, Lydia T., Vicki Roth, and J. A. Kampmeier. "Implementation of a peer-led team learning instructional approach in an undergraduate organic chemistry course." Journal of Research in Science Teaching 39, no. 7 (2002): 606-632.

14. Pazos, Pilar, Marina Micari, and Gregory Light. "Developing an instrument to characterise peer-led groups in collaborative learning environments: assessing problem-solving approach and group interaction." Assessment \& Evaluation in Higher Education 35, no. 2 (2010): 191-208.

15. Hmelo-Silver, Cindy E., Ravit Golan Duncan, and Clark A. Chinn. "Scaffolding and achievement in problem-based and inquiry learning: A response to Kirschner, Sweller, and Clark (2006)." Educational Psychologist 42, no. 2 (2007): 99-107.

16. Quintana, Chris, Brian J. Reiser, Elizabeth A. Davis, Joseph Krajcik, Eric Fretz, Ravit Golan Duncan, Eleni Kyza, Daniel Edelson, and Elliot Soloway. "A scaffolding design framework for software to support science inquiry." The Journal of the Learning Sciences 13, no. 3 (2004): 337-386.

17. Marks, Michelle A., John E. Mathieu, and Stephen J. Zaccaro. "A temporally based framework and taxonomy of team processes." Academy of Management Review 26, no. 3 (2001): 356-376.

18. LePine, Jeffery A., Ronald F. Piccolo, Christine L. Jackson, John E. Mathieu, and Jessica R. Saul. "A meta-analysis of teamwork processes: tests of a multidimensional model and relationships with team effectiveness criteria." Personnel Psychology 61, no. 2 (2008): 273-307.

19. Rousseau, Vincent, Caroline Aubé, and André Savoie. "Teamwork behaviors a review and an integration of frameworks." Small Group Research 37, no. 5 (2006): 540-570.

20. Pazos, Pilar. "Conflict management and effectiveness in virtual teams." Team Performance Management: An International Journal 18, no. 7/8 (2012): 401-417.

21. Pazos, P., and M. Beruvides. "Incorporating training and feedback into the study of patterns in group decision making: The impact of communication medium." Team Performance Management 17, no. 1/2 (2011): 83-101.

22. DeSanctis, Gerardine, and Marshall Scott Poole. "Capturing the complexity in advanced technology use: Adaptive structuration theory." Organization Science 5, no. 2 (1994): 121-147.

23. Venkatesh, Viswanath, Michael G. Morris, Gordon B. Davis, and Fred D. Davis. "User acceptance of information technology: Toward a unified view." MIS Quarterly (2003): 425-478.

24. Stevens, Michael J., and Michael A. Campion. "The knowledge, skill, and ability requirements for teamwork: Implications for human resource management." Journal of Management 20, no. 2 (1994): 503-530.

25. Stevens, Michael J., and Michael A. Campion. "Staffing work teams: Development and validation of a selection test for teamwork settings." Journal of Management 25, no. 2 (1999): 207-228.

26. McClough, Anita C., and Steven G. Rogelberg. "Selection in teams: An exploration of the teamwork knowledge, skills, and ability test." International Journal of Selection and Assessment 11, no. 1 (2003): 56-66. 